Article

\title{
Relationships Between Chemical Structure and Antioxidant Activity of Isolated Phytocompounds from Lemon Verbena
}

\author{
Noelia Sánchez-Marzo ${ }^{1}$, Jesús Lozano-Sánchez ${ }^{2,3, * \mathbb{C}}$, María de la Luz Cádiz-Gurrea ${ }^{3,4}{ }^{\circledR}$, \\ María Herranz-López ${ }^{1}$ (D), Vicente Micol ${ }^{1,5}{ }^{(\mathbb{D}}$ and Antonio Segura-Carretero ${ }^{3,4}$ \\ 1 Instituto de Biología Molecular y Celular (IBMC) and Instituto de Investigación, Desarrollo e Innovación en \\ Biotecnología Sanitaria de Elche (IDiBE), Universitas Miguel Hernández, 03202 Elche, Spain \\ 2 Department of Food Science and Nutrition, University of Granada, Campus of Cartuja, 18071 Granada, Spain \\ 3 Research and Development of Functional Food Centre (CIDAF), PTS Granada, Avda. Del Conocimiento s/n., \\ Edificio BioRegion, 18016 Granada, Spain \\ 4 Department of Analytical Chemistry, University of Granada, C/Fuentenueva s/n, 18071 Granada, Spain \\ 5 CIBER: CB12/03/30038, Fisiopatología de la Obesidad y la Nutrición, CIBERobn, \\ Instituto de Salud Carlos III (ISCIII), 07122 Palma de Mallorca, Spain \\ * Correspondence: jesusls@ugr.es; Tel.: +34-958-637083; Fax: +34-958-249510
}

Received: 29 July 2019; Accepted: 17 August 2019; Published: 20 August 2019

check for updates

\begin{abstract}
Over the last few years, people have been concerned about the narrow relationship between nutrition and health leading to an increasing demand of nutraceutical products and functional food. Lemon verbena (Lippia citriodora Kunth) has been traditionally used for respiratory, digestive, and muscular diseases, showing effects that are promoted by the antioxidant activity of its phytoconstituents. The antioxidant power of several lemon verbena extracts has been tested but its isolated compounds activity has not been described. The aim of the present work was to isolate phytochemicals from a commercial lemon verbena extract through a semi-preparative high-performance liquid chromatography approach for further evaluation of its individual antioxidant activity using three different methods. The structure-antioxidant activity relationships revealed the influence of substitutions in the strong antioxidant power exerted by glycosylated phenylpropanoids, in contrast to the low antioxidant capacity showed by iridoids. Development of enriched extracts in these compounds could lead to greater antioxidant effects and improved functional ingredients to prevent chronic diseases.
\end{abstract}

Keywords: lemon verbena; RP-HPLC-ESI-TOF-MS; semi-preparative chromatography; isolation; antioxidant; structure-activity relationship

\section{Introduction}

Combinatory chemistry has demonstrated to be insufficient for designing bioactive molecules and there is growing interest in discovering new compounds from natural sources. Plants have been used for centuries in traditional medicine, so they constitute a very attractive source for elucidating new structures that could interact with human biomolecules.

One well-known medicinal plant is lemon verbena, with scientific names of Lippia citriodora (Kunth), Aloysia citriodora (Paláu), and Aloysia triphylla (L'Hérit). It belongs to the family Verbenaceae (Lamiales order) and is native from South America but is also cultivated in southern Europe and northern Africa. Lemon verbena was widely employed for stomach and nervous disorders by the Inca culture and there are reports of this specie from the 17th century [1]. Several studies have been reported its beneficial effects, including antimicrobial, neuroprotective, cardioprotective, anticonvulsant, 
anti-inflammatory, and antigenotoxic among others recently reviewed by Bahramsoltani et al. [2]. The biological activity of this plant has been demonstrated in vitro and in vivo [3,4]. Furthermore, eight clinical trials have been carried out using lemon verbena extracts [5-12]. Most of them lasted 21-28 days and no adverse effects were reported, showing the safety of those extracts. Four of the clinical studies were related to the antioxidant power of lemon verbena, increasing the activity of antioxidant enzymes such as glutathione reductase and glutathione peroxidase while oxidation markers in plasma, i.e., protein carbonyls and malondialdehyde, were diminished [6-9].

Oxidative stress is involved in important chronic disorders such as neurodegenerative diseases, obesity, and cancer. Reactive oxygen species (ROS) are the most studied components of oxidative stress and can damage proteins, lipids, and DNA [13]. ROS not only cause DNA oxidation products but can also affect DNA repair proteins, compromising their efficiency and leading in carcinogenesis [14]. Furthermore, the overproduction of ROS alters important metabolic pathways and induces the expression of inflammatory mediators [15]. In this context, antioxidants could prevent the development of chronic conditions. Lemon verbena has shown its antioxidant potential as it has been tested on an insulin-resistant hypertrophic 3T3-L1-adipocyte model and colon cancer cells, exhibiting promising results $[2,16]$.

Various categories of phytochemicals have been described in different parts of L. citriodora, including terpenoids and phenolic compounds, which are the most relevant groups of bioactive compounds [17]. Fatty alcohols and ketones have also been identified [18,19]. Verbascoside, also named acteoside, a polyphenol from the phenylpropanoids subgroup, is the most abundant compound in lemon verbena leaves so that the related biological effects are mainly attributed to this phytochemical. The antioxidant power of isolated verbascoside has been extensively studied [20-22]. Nevertheless, no data are available on the antioxidant activity of other compounds from lemon verbena that could be responsible of the observed effects.

Due to the lack of commercial standards, isolating compounds from original extracts is necessary for studying the bioactivity on their own and exploring structure-activity relationships. One of the most efficient techniques to fractionate extracts is (semi-)preparative liquid chromatography (LC), and C18 reversed phase (RP) columns offer high versatility to purify terpenoids and phenolic compounds [23]. C18-RP columns are also employed to characterize the composition of whole extracts and collected fractions by high-pressure liquid chromatography (HPLC). This separation methodology can be coupled to different detection systems and constitute a very useful analytical tool. Ultraviolet and diodo-array detectors (DAD) allow the detection of phenolic compounds but mass spectrometry (MS) provides information about their molecular weight and structure [24]. Moreover, the most probable molecular formula can be deduced through MS with a time-of-flight (TOF) analyzer from accurate mass data and its elevated sensitivity [25].

There are well-established methods to examine the antioxidant capacity of whole extracts and isolated compounds in vitro [26]. They can differ in the mechanism of reduction of generated oxidant species by the assessed compounds, and single electron transfer (SET) methods can be distinguished from those based on hydrogen atom transfer (HAT).

Hence, the aims of the present study were: (1) To characterize the composition of a commercial lemon verbena extract using HPLC coupled to a TOF mass spectrometer with an electrospray ionization (ESI) interface, (2) to obtain different fractions from the extract by semi-preparative HPLC and to analyze their composition by HPLC-ESI-TOF-MS, and (3) to examine the antioxidant activity of the whole extract and the fractions by three different methods for clarifying structure-activity relationships.

\section{Materials and Methods}

\subsection{Chemicals}

Acetic acid and methanol were purchased from Fluka (Sigma-Aldrich, Steinheim, Germany) and Lab-Scan (Gliwice, Poland), respectively. Both solvents were of HPLC-MS grade and the water 
for all experiments was purified by a Milli-Q system from Millipore (Bedford, MA, USA). For the antioxidant assays, ABTS [2,2'-azinobis (3-ethylbenzothiazoline-6-sulfonate)], Trolox (6-hydroxy2,5,7,8-tetramethylchroman-2-carboxylic acid), AAPH (2,2'-azobis-2-methyl-propanimidamide, dihydrochloride), TPTZ (2,4,6-tripyridyl-S-triazine), ferric sulfate, potassium persulfate and fluorescein were obtained from Sigma-Aldrich (St. Louis, MO, USA). The rest of reagents needed for measuring the antioxidant activity were provided from Panreac (Barcelona, Spain): Ferric chloride, hydrochloric acid, sodium acetate, trihydrated sodium acetate and dehydrated sodium phosphate.

\subsection{Sample Preparation}

A commercial extract (PLX $\left.{ }^{\circledR} 10\right)$ of Lippia citriodora was used in this work containing $10 \%$ verbascoside, as declared by the manufacturer (Monteloeder, Elche, Spain).

For analytical characterization, $5 \mathrm{mg}$ of extract were dissolved in $1 \mathrm{~mL}$ of water. After $1 \mathrm{~min}$ of vortex and sonication for $20 \mathrm{~s}$, the result solution was filtered through a $0.25 \mathrm{~mm}$ filter before the HPLC analysis. Meanwhile, a solution of lemon verbena extract at $50 \mathrm{mg} / \mathrm{mL}$ was prepared in water for its fractionation by semi-preparative HPLC. This solution was vortexed for $2 \mathrm{~min}$, was sonicated for $20 \mathrm{~s}$ and then was filtered employing the mentioned filter.

\subsection{Instrumentation}

Different fractions of the L. citriodora extract were recovered using a Gilson preparative HPLC system (Gilson Inc., Middleton, WI, USA) which equipped with automated liquid handling solutions (model GX-271), a binary pump (model 331/332) and UV-vis detector (model UV-Vis 156). The solvent of the collected fractions was evaporated in a Savant Speed Vac Concentrator SC250 EXP (Thermo Scientific, Waltham, MA, USA).

The composition of the whole extract and the fractions was analyzed through a HPLC-ESI-TOF-MS system. The chromatographic separation was carried out using an Agilent 1200 series rapid-solution LC equipment (Agilent Technologies, Palo Alto, CA, USA) with an autosampler, a binary pump and a diode-array detector (DAD).

Both HPLC systems were coupled to a time-of-flight (TOF) mass spectrometer (Bruker Daltonics, Bremen, Germany) with an electrospray ionization (ESI) interface (model G1607A, Agilent Technologies, Palo Alto, CA, USA). Calibration solution was injected at the beginning of each analysis by a 74900-00-05 Cole-Palmer syringe pump (Cole-Palmer, Vernon Hills, IL, USA) directly connected to the interface.

Finally, absorbance and fluorescence measurements for the antioxidant assays were performed on a Synergy Mx Monochromator-Based Multi-Mode Micro plate reader (Bio-Tek instruments Inc., Winooski, VT, USA) in 96-well microplates.

\subsection{Chromatographic and UV Conditions}

The separation of the compounds present in the lemon verbena extract and the collected fractions was performed at room temperature using a Zorbax Eclipse Plus C18 column $(1.8 \mu \mathrm{m}, 150 \times 4.6 \mathrm{~mm})$. The mobile phase consisted of acetic acid $0.5 \%$ in water as eluent $A$ and methanol as eluent $B$. The flow rate was set at $0.4 \mathrm{~mL} / \mathrm{min}$ and the following multi-step linear gradient was employed: $0 \mathrm{~min}, 5 \% \mathrm{~B}$; $3 \mathrm{~min}, 10 \% \mathrm{~B} ; 5 \mathrm{~min}, 14 \% \mathrm{~B} ; 15 \mathrm{~min}, 20 \% \mathrm{~B} ; 17 \mathrm{~min}, 23 \% \mathrm{~B} ; 29 \mathrm{~min}, 35 \% \mathrm{~B} ; 36 \mathrm{~min}, 38 \% \mathrm{~B} ; 52 \mathrm{~min}, 60 \%$ B; $54 \mathrm{~min}, 95 \% \mathrm{~B} ; 56 \mathrm{~min}, 5 \% \mathrm{~B} ; 65 \mathrm{~min}, 5 \% \mathrm{~B}$. The initial conditions were maintained for $10 \mathrm{~min}$ and the injection volume was $10 \mu \mathrm{L}$. The spectrum range of 190-950 $\mathrm{nm}$ was monitored by the DAD detector.

\subsection{Fractionation of Phytochemicals}

The lemon verbena extract was fractionated with the aim of obtaining isolated compounds. The separation was carried out using a semi-preparative Ascentis C18 column $(10 \mu \mathrm{m}, 250 \times 212 \mathrm{~mm})$ at room temperature. The mobile phase used was the same than for the analytical characterization, acetic acid $0.5 \%(\mathrm{~A})$ and methanol (B), and the following multi-step linear gradient was applied: $0 \mathrm{~min}$, $5 \%$ B; 15 min, 20\% B; 21 min, 23\% B; 28 min, 25\% B; 32 min, 32\% B; $52 \mathrm{~min}, 40 \%$ B, 69 min, $60 \%$ B; 71 min, 
$65 \% \mathrm{~B} ; 75 \mathrm{~min}, 100 \% \mathrm{~B} ; 80 \mathrm{~min}, 5 \% \mathrm{~B} ; 84 \mathrm{~min}, 5 \% \mathrm{~B}$. In this case, the flow rate used was $10 \mathrm{~mL} / \mathrm{min}$ and the injected volume was $500 \mu \mathrm{L}$. The UV-vis detector of the Gilson preparative HPLC system was set at 240 and $280 \mathrm{~nm}$. The fraction collection step consisted of mass spectrometry (MS)-based purification, determining the elution time window for collecting the target compound. A total of 19 fractions were obtained and their solvent was evaporated at $35^{\circ} \mathrm{C}$ under vacuum. The residue of each fraction was dissolved in water at a final concentration of $1 \mathrm{mg} / \mathrm{mL}$. The result solutions were filtered through a $0.25 \mathrm{~mm}$ filter and were stored at $-20^{\circ} \mathrm{C}$ until their characterization and further antioxidant evaluation.

\subsection{ESI-TOF-MS Detection}

HPLC systems were coupled to a TOF mass spectrometer in which a stable spray was ensured with a flow of $0.2 \mathrm{~mL} / \mathrm{min}$. For that reason, a splitter for both, analytical, and semipreparative HPLC systems, was used in the coupling with the MS detector (make-up pump equipped with a MRA splitter, model 307, Gilson, Middleton, WI, USA).

The ESI interface operated in negative ion mode, setting a capillary voltage of $+4.5 \mathrm{kV}$ and other source parameters were optimized. Briefly, the drying gas temperature and flow were $210^{\circ} \mathrm{C}$ and $9 \mathrm{~L} / \mathrm{min}$, respectively, and nebulizing gas pressure was 2.3 bar. The following values were set concerning the transfer parameters: Capillary exit, $-120 \mathrm{~V}$; skimmer 1, $-40 \mathrm{~V}$; skimmer 2, $-22.5 \mathrm{~V}$; hexapole 1,-23 V; hexapole 2, $-20 \mathrm{~V}$.

Data were acquired considering a $m / z$ range of $50-1000$. The accurate mass data of the molecular ions were processed through the software DataAnalysis 4.0 (Bruker Daltonics, Bremen, Germany) and its Generate Molecular Formula Editor provided possible elemental formulas with high confidence through comparison of the theorical and the measured isotope pattern ( $\sigma$ value). The accuracy threshold was established at $5 \mathrm{ppm}$ as it is widely accepted [27]. All spectra were calibrated prior to the compound identification through a sodium formate cluster as calibration solution, containing $5 \mathrm{mM}$ sodium hydroxide and $0.2 \%$ acetic acid in water:isopropanol $1: 1 \mathrm{v} / \mathrm{v}$, injected at the beginning of each run.

\subsection{Antioxidant Activity Assays}

The antioxidant activity of the lemon verbena extract and the obtained fractions was evaluated. Two single-electron transfer (SET) based methods were developed-the ferric ion reducing antioxidant power (FRAP) and the trolox equivalent antioxidant capacity (TEAC) assays-the while oxygen radical absorbance capacity (ORAC) method was also performed as a hydrogen-atom transfer (HAT) based test.

\subsubsection{Ferric-Reducing Ability Power Assay (FRAP)}

The FRAP assay was carried out following the method described by Benzie and Strain [28]. Reduction of a ferric-tripyridyltriazine complex was estimated mixing the samples with freshly prepared FRAP reagent and measuring the absorbance at $593 \mathrm{~nm}$ for $4 \mathrm{~min}$. A standard curve of $\mathrm{FeSO}_{4} \cdot 7 \mathrm{H}_{2} \mathrm{O}$ was assessed and results were expressed as millimoles of $\mathrm{Fe}^{2+}$ equivalents (FE) per gram of extract or fraction (dry weight, $\mathrm{dw}$ ).

\subsubsection{Trolox Equivalent Antioxidant Capacity (TEAC)}

The TEAC assay was originally described by Miller et al. and was performed as modified by Cádiz-Gurrea et al. [29,30]. This method consists of the ABTS [2,2' -azinobis-(3-ethylbenzothiazoline6-sulphonate)] radical cation (ABTS ${ }^{+}$) scavenging activity of the samples. Briefly, ABTS stock solution was prepared with $2.45 \mathrm{mM}$ potassium persulfate to generate the radical cation specie. After 12-24 h in darkness at room temperature, the absorbance value of the resulting $\mathrm{ABTS}^{+\bullet}$ solution was adjusted to $0.70( \pm 0.02)$ at $734 \mathrm{~nm}$ through water dilution prior its use. Samples were mixed with this solution and runs were performed at $734 \mathrm{~nm}$ and $25^{\circ} \mathrm{C}$ after $5 \mathrm{~min}$ of reaction. A standard curve of trolox was 
prepared for expressing the antioxidant activities as millimoles of trolox equivalents (TE) per gram of extract or fraction $(\mathrm{dw})$.

\subsubsection{Oxygen Radical Absorbance Capacity (ORAC)}

The ORAC method developed by Ou el al. was performed to assay the capacity of the samples to scavenge peroxyl radicals with some modifications as Cádiz-Gurrea et al. reported [30,31]. A freshly prepared AAPH solution was used for generating peroxyl radicals and fluorescein oxidation was monitored at $37^{\circ} \mathrm{C}$ with $495 \mathrm{~nm}$ excitation and $520 \mathrm{~nm}$ emission filters. In this case, trolox was also used as reference compound and a regression equation between its concentration and the net area of the fluorescence decay curve (area under curve, AUC) was employed to calculate the final ORAC values of the samples expressed as $\mathrm{mmol} \mathrm{TE} / \mathrm{g}(\mathrm{dw})$.

\section{Results and Discussion}

\subsection{Characterization of A L. citriodora Extract by HPLC-ESI-TOF-MS}

A commercial L. citriodora was characterized through mass spectrometry detection after chromatographic separation of its constituents with a reversed phase. Figure 1 shows the base peak chromatogram (BPC) corresponding to negative polarity. A total of 30 compounds were tentatively identified and were numbered according to their elution order.

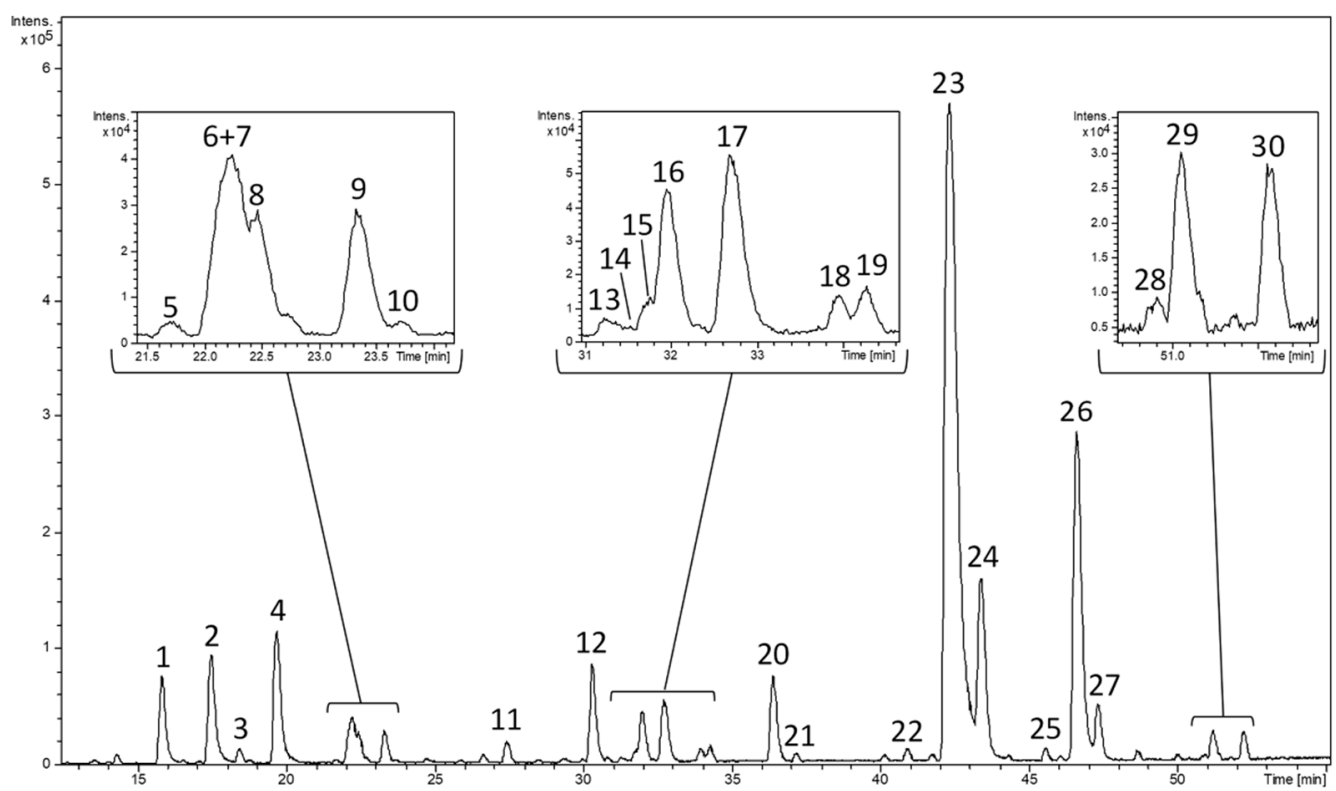

Figure 1. Base peak chromatogram (BPC) of a commercial lemon verbena extract (PLX $\left.{ }^{\circledR} 10\right)$ at $5 \mathrm{mg} / \mathrm{mL}$ obtained by high-pressure liquid chromatography (HPLC)-electrospray ionization interface (ESI)-time-of-flight (TOF)-mass spectrometry (MS) in negative ion mode. Peak numbers correspond to those of Table 1 according to the elution order.

Table 1 includes the information provided by the analytical system including the retention time, the mass spectral data (experimental and calculated $\mathrm{m} / \mathrm{z}$, mass error, and $\sigma$ values) and the molecular formula predicted by the software for each peak. The elution order, UV-vis spectra, MS data, and information provided from literature were taken into consideration to assign the proposed compounds. Iridoids, glycosylated phenylpropanoids, and flavonoids were mainly found. 
Table 1. Retention time (RT) and mass spectral data of the compounds characterized in the commercial lemon verbena extract (PLX $\left.{ }^{\circledR} 10\right)$ by reversed phase (RP)-HPLC-ESI-TOF-MS in negative mode.

\begin{tabular}{|c|c|c|c|c|c|c|c|c|}
\hline Peak & RT (min) & $\begin{array}{c}{[\mathrm{M}-\mathrm{H}]-} \\
\text { Measured }\end{array}$ & $\begin{array}{c}{[\mathrm{M}-\mathrm{H}]-} \\
\text { Calculated }\end{array}$ & Error (ppm) & mSigma & $\begin{array}{l}\text { Molecular } \\
\text { Formula }\end{array}$ & Proposed Compound & Matrix \\
\hline 1 & 15.85 & 391.1236 & 391.1246 & 2.5 & 1.9 & C 16 H 24 O11 & Shanziside & L. citriodora \\
\hline 2 & 17.51 & 373.1122 & 373.114 & 4.9 & 3.1 & C $16 \mathrm{H} 22 \mathrm{O} 10$ & Gardoside & L. citriodora \\
\hline 3 & 18.46 & 387.0934 & 387.0933 & -0.3 & 5.7 & C $16 \mathrm{H} 20 \mathrm{O} 11$ & Ixoside & L. citriodora \\
\hline 4 & 19.62 & 461.1654 & 461.1664 & 2.3 & 3.2 & C $20 \mathrm{H} 30 \mathrm{O} 12$ & Verbasoside & L. citriodora \\
\hline 5 & 21.72 & 299.1116 & 299.1136 & 6.7 & 3.9 & $\mathrm{C} 14 \mathrm{H} 20 \mathrm{O} 7$ & Salidroside & S. viridis, E. rostkoviana, O. fragans \\
\hline 6 & 22.14 & 487.1435 & 487.1457 & 4.6 & 1.6 & C $21 \mathrm{H} 28 \mathrm{O} 13$ & Cistanoside F (isomer) & L. citriodora \\
\hline 7 & 22.22 & 487.1433 & 487.1457 & 5 & 4.1 & C $21 \mathrm{H} 28 \mathrm{O} 13$ & Cistanoside $\mathrm{F}$ (isomer) & L. citriodora \\
\hline 8 & 22.46 & 375.1285 & 375.1297 & 3 & 4.3 & C 16 H 24 O 10 & Epiloganic acid & L. graveolens \\
\hline 9 & 23.33 & 375.1279 & 375.1297 & 4.8 & 3.9 & C $16 \mathrm{H} 24 \mathrm{O} 10$ & Loganic acid & L. citriodora \\
\hline 10 & 23.71 & 373.1124 & 373.114 & 8.8 & 160.1 & C 16 H $22 \mathrm{O} 10$ & Secologanic acid & L. graveolens \\
\hline 11 & 27.74 & 405.139 & 405.1402 & 3 & 2.9 & C 17 H 26 O 11 & Shanziside methyl ester & L. citriodora, L. alba \\
\hline 12 & 30.28 & 389.1088 & 389.1089 & 0.3 & 3.1 & C 16 H 22 O 11 & Theveside & L. citriodora \\
\hline 13 & 31.29 & 489.1608 & 489.1614 & 1.1 & 3.3 & C $21 \mathrm{H} 30 \mathrm{O} 13$ & Teucardoside & L. citriodora, T. polium \\
\hline 14 & 31.51 & 387.1654 & 387.1661 & 1.7 & 18.9 & C $18 \mathrm{H} 28 \mathrm{O} 9$ & Tuberonic acid glucoside (isomer) & L. citriodora \\
\hline 15 & 31.76 & 445.2068 & 445.2079 & 2.5 & 24.6 & $\mathrm{C} 21 \mathrm{H} 34 \mathrm{O} 10$ & Sacranoside A & L. citriodora \\
\hline 16 & 31.96 & 387.1654 & 387.1661 & 1.8 & 3.5 & $\mathrm{C} 18 \mathrm{H} 28 \mathrm{O} 9$ & Tuberonic acid glucoside (isomer) & L. citriodora \\
\hline 17 & 32.69 & 387.2007 & 387.2024 & 4.6 & 1.4 & C $19 \mathrm{H} 32 \mathrm{O} 8$ & UK & \\
\hline 18 & 33.93 & 639.1928 & 639.1931 & 0.5 & 30.6 & С $29 \mathrm{H} 36$ O 16 & b-hydroxy-(iso)-verbascoside & L. citriodora \\
\hline 19 & 34.25 & 639.1931 & 639.1931 & 0 & 41.7 & С 29 H 36 O 16 & b-hydroxy-(iso)-verbascoside & L. citriodora \\
\hline 20 & 36.36 & 637.1049 & 637.1046 & -0.5 & 2.1 & C 27 H 26 O 18 & Luteolin-7-diglucuronide & L. citriodora \\
\hline 21 & 37.12 & 521.2016 & 521.2028 & 2.5 & 3.4 & C $26 \mathrm{H} 34 \mathrm{O} 11$ & Lariciresinol-4-O- $\beta$-D-glucopyranoside & L. graveolens \\
\hline 22 & 40.85 & 621.1102 & 621.1097 & -0.8 & 7 & C 27 H 26 O 17 & Apigenin-7-diglucuronide & L. citriodora \\
\hline 23 & 42.24 & 623.1999 & 623.1981 & -2.9 & 3 & С 29 H 36 O 15 & Verbascoside & L. citriodora \\
\hline 24 & 43.33 & 651.1228 & 651.1203 & -3.9 & 4.2 & C $28 \mathrm{H} 28 \mathrm{O} 18$ & Chrysoeriol-7-diglucuronide & L. citriodora \\
\hline 25 & 45.29 & 621.1827 & 621.1766 & -9.9 & 83.4 & $\mathrm{C} 36 \mathrm{H} 30 \mathrm{O} 10$ & Diooflavone & L. citriodora \\
\hline 26 & 46.54 & 623.1988 & 623.1981 & -1 & 3.3 & C $29 \mathrm{H} 36 \mathrm{O} 15$ & Isoverbascoside & L. citriodora \\
\hline 27 & 47.24 & 637.215 & 637.2138 & -2 & 5.2 & C $30 \mathrm{H} 38 \mathrm{O} 15$ & Leucosceptoside A & L. citriodora, L. alba, L. multiflora \\
\hline 28 & 50.8 & 637.2142 & 637.2138 & -0.6 & 4.8 & С $30 \mathrm{H} 38$ O 15 & Isoleucosceptoside A & C. spinosum, Globularia spp. \\
\hline 29 & 51.1 & 635.1271 & 635.1254 & -2.7 & 6.1 & C $28 \mathrm{H} 28 \mathrm{O} 17$ & Acacetin-7-diglucuronide & L. citriodora \\
\hline 30 & 54.63 & 651.2299 & 651.2294 & -0.7 & 3.8 & C 31 H 40 O 15 & Martynoside & L. citriodora \\
\hline
\end{tabular}




\subsubsection{Iridoids}

Most compounds that were eluted firstly were characterized as iridoids. Shanziside $(\mathrm{m} / z$ 391), gardoside $(\mathrm{m} / \mathrm{z} 373)$, ixoside $(\mathrm{m} / \mathrm{z} 387)$ and theveside $(\mathrm{m} / \mathrm{z} 389)$ were tentatively identified for peaks $1-3$ and 12 , respectively. These compounds were previously described in L. citriodora by other authors who considered the fragmentation patterns (MS/MS) [17,32].

Furthermore, not only loganic acid (peak 9) but also epiloganic acid (peak 8) and secologanic acid (peak 10) were found. Loganic acid $(m / z$ 375) had been previously reported in L. citriodora but, as far as we are concerned, epiloganic $(\mathrm{m} / \mathrm{z} 375)$ and secologanic $(\mathrm{m} / \mathrm{z} 373)$ acids have never been described in this specie [33]. Epiloganic and secologanic acids were characterized in Lippia graveolens leaves using nuclear magnetic resonance spectroscopy (NMR) [34]. Both compounds were tentatively proposed on basis of the data provided by the mass spectrometer and their elution order was corroborated with another study [35].

The peak 11 was identified as shanziside methyl ester $(\mathrm{m} / \mathrm{z} 405)$ which has been found in different species from Lippia genus as L. citriodora and L. alba [33,36]. For peak 13, teucardoside $(\mathrm{m} / \mathrm{z} 489)$ was tentatively postulated on basis of its presence in other species from Lamiales order as other authors also indicated in a previous report [37].

\subsubsection{Glycosylated Phenylpropanoids}

A total of ten compounds were identified as glycosylated phenylpropanoids, which constitute an abundant group of phenolic compounds in lemon verbena as it is described in the bibliography [32]. The most intense peak (peak 23) was proposed as verbascoside and the second most intense one (peak 26) was associated with its isomer isoverbascoside, presenting both $\mathrm{m} / \mathrm{z}$ values at 623 . Their $\beta$-hydroxyverbascoside and $\beta$-hydroxyisoverbascoside derivatives were postulated for peaks 18/19 ( $m / 2$ 639). Their identical mass spectra and close elution time did not allow their particular identification in our work. Indeed, the fragmentation pattern of these two derivatives generates identical fragments which did not allow their distinction through MS/MS in a previous characterization of L. citriodora [17]. In that study, verbasoside $(m / z 461)$ and martynoside $(m / z 651)$ were also described corresponding to peaks 4 and 30 of the present work, respectively.

The same molecular formula was predicted for peaks 6 and 7. Both compounds were postulated as cistanoside $\mathrm{F}$ isomers $(\mathrm{m} / \mathrm{z} 487)$ according to the literature [33,38]. The peak 27 was identified as leucosceptoside A ( $\mathrm{m} / \mathrm{z}$ 637) which has been reported in L. citriodora, L. alba and L. multiflora [39-41].

In contrast, isoleucosceptoside A ( $m / z 637)$, corresponding to peak 28 , has been tentatively proposed for the first time in the Lippia genus. This compound, also named plantanoside C, was characterized using NMR in Citharexylum spinosum which also belongs to Verbenaceae family [42]. The elution order of isoleucosceptoside A was consistent with another study using Globularia spp. (Lamiales order) where other common compounds were also described (gardoside, verbascoside, and leucosceptoside A) [43]. A maximum absorbance of $280 \mathrm{~nm}$ was observed for this peak corroborating its phenolic structure (Supplementary Figure S1).

\subsubsection{Flavonoids}

Four flavonoids belonging to flavones subclass were identified in the lemon verbena extract, as were described in other works [17,32]. These flavones were luteolin-7-diglucuronide (peak 20, $m / z$ 637), apigenin-7-diglucuronide (peak 22, m/z 621), chrysoeriol-7-diglucuronide (peak 24, m/z 651), and acacetin-7-diglucuronide (peak 29, m/z 635). Glucuronidation occurs in plants for enhancing the flavonoid solubility in water and favoring its accumulation in vacuoles [44]. Moreover, diooflavone $(\mathrm{m} / \mathrm{z}$ 621) that is a biflavonoid was also detected (peak 25) in the present work as occurred in other lemon verbena extract characterization [33]. 


\subsubsection{Other Compounds}

Three monoterpenoids were found in their glycosylated form, sacranoside A (peak $15, \mathrm{~m} / \mathrm{z} 445$ ) and two tuberonic acid glucoside isomers (peaks 14 and 16, $\mathrm{m} / \mathrm{z} 387$ ), that have been described in bibliography related to L. citriodora [33]. Peak 21 was tentatively proposed lariciresinol-4-O- $\beta$-D-glucopyranoside $(\mathrm{m} / \mathrm{z}$ 521) which belongs to lignans and has been identified in L. graveolens through NMR and circular dichroism [45].

Furthermore, the molecular formula generated for peak $5(\mathrm{~m} / \mathrm{z} 299)$ and the literature allowed for its tentative identification as salidroside for the first time in this specie. Salidroside is a tyrosol (simple phenol) derivative which is present in some lamial species [46-48]. Peak 5 presented an absorbance maximum at $280 \mathrm{~nm}$ that is the maximum wavelength of absorption observed in tyrosol and its derivatives (Supplementary Figure S1).

Nevertheless, retention time, UV absorption, and mass spectra were not sufficient for the identification of peak $17(\mathrm{~m} / \mathrm{z} 373)$, contrasting with literature and databases. Additional information on fragmentations in MS/MS experiments is required for their elucidation.

\subsection{Fractionation of the Lemon Verbena Extract Using Semi-Preparative Chromatography}

The compounds in the lemon verbena extract were isolated through a semi-preparative HPLC methodology Previously, the optimization of the developed analytical method was required in the scaled-up process. Columns with higher particle size are used in (semi-) preparative chromatography. This fact causes lower peak resolution but its bigger capacity leads to a higher amount of compound obtained per unit time. On the other hand, longer columns provide greater resolution [49]. For these reasons, the optimization of the semi-preparative method was required in the scaled-up process.

In our study, a semi-preparative C18 $(250 \times 212 \mathrm{~mm})$ column with $10 \mu \mathrm{m}$ particle-size was used. The optimum solvents to be used as a mobile phase were based on the analytical chromatographic conditions maintaining the composition of the eluent A (acetic acid $0.5 \%$ in water) and B (methanol). Regular methods to isolate phenolics by HPLC used mainly gradient elution. An initial linear gradient time of $85 \mathrm{~min}$ and the flow-rate at $15 \mathrm{~mL} / \mathrm{min}$ were used (Figure 2A). Then, the linear gradient was adapted to the new column characteristics to achieve the best separation results. The change of gradient affects the retention times and the chromatographic separation of the target compounds, so that testing of different experimental multi-step gradients was required. The best results were achieved with that detailed in the Materials and Methods section in comparison with other three different tested gradients. It is worth clarifying that the higher injected amount of extract influences the peak resolution as well. To increase the resolution among the peaks, the injected concentration was reduced from 75 to $50 \mathrm{mg} / \mathrm{mL}$ and the final flow rate used was $10 \mathrm{~mL} / \mathrm{min}$ (Figure 2B). The final multi-step linear gradient allowed the separation of peaks 8-9, 16-17, 24, and 27 (according to the numeration of Table 1).

Afterwards, the collection of fractions was carried out taking into account the UV and MS information (Figure 3). The composition of the 19 obtained fractions was analyzed by the detailed HPLC-ESI-TOF-MS method (Table 2 and Supplementary Figure S2). Fractions were named as F1-F19 according to their elution order. The residue weight allowed the estimation of the relative amount of each compound(s). The major quantity of compound was obtained for verbascoside with $2.3 \mathrm{mg}$ which suppose $9.2 \%$ of the injected amount of extract, close to the $10 \%$ declared by the manufacturer. The collected amount of some compounds that are not commercially available, as shanziside methyl ester or theveside, is worthy of consideration. 


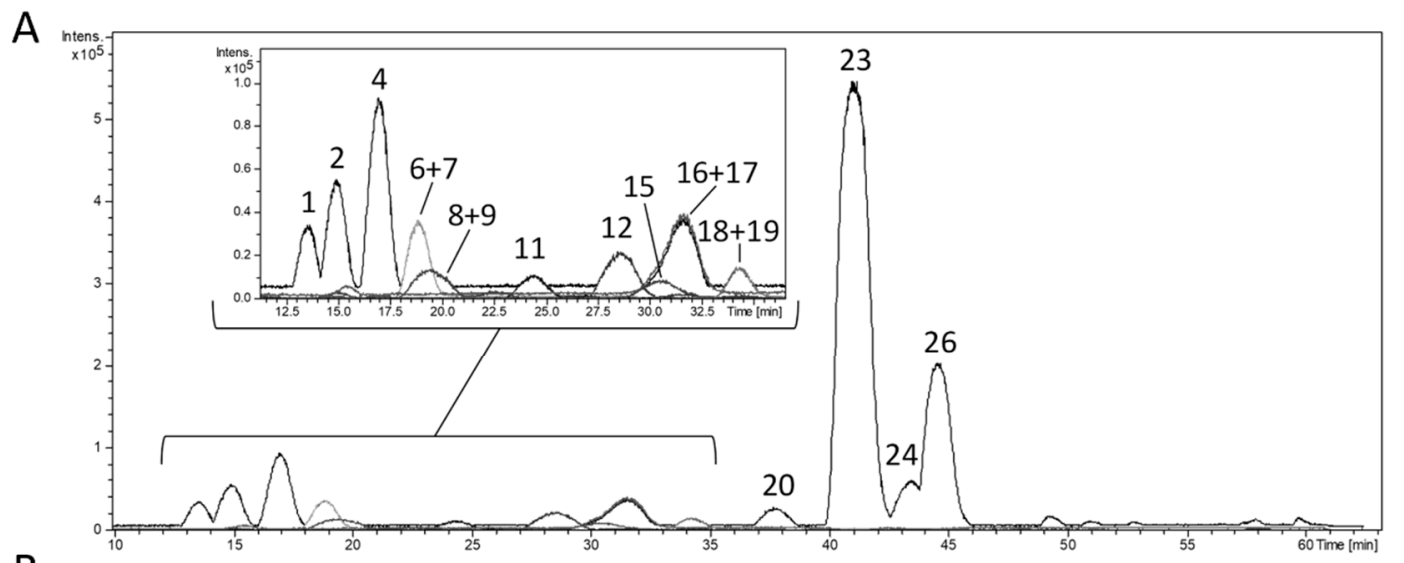

B

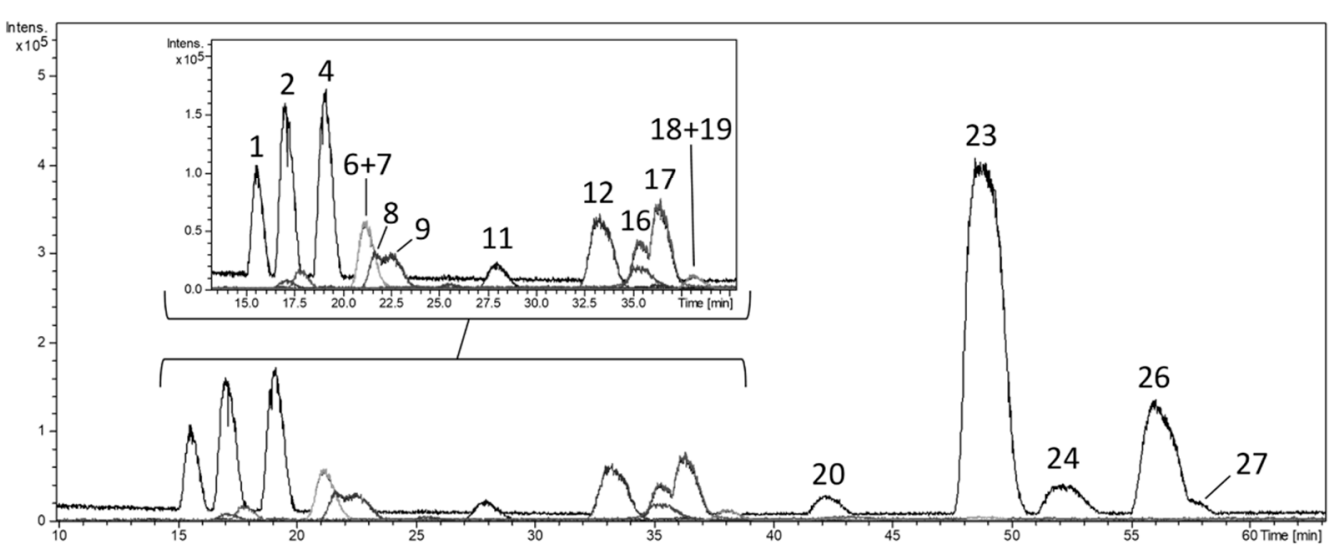

Figure 2. Base peak chromatogram (BPC) of a commercial lemon verbena extract (PLX $\left.{ }^{\circledR} 10\right)$ at $50 \mathrm{mg} / \mathrm{mL}$ obtained by semi-preparative HPLC-ESI-TOF-MS in negative ion mode applying (A) the initial multi-step lineal gradient from the analytical HPLC method, and (B) the final multi-step lineal gradient after optimization. Peak numbers correspond to those of Table 1.

Table 2. Collected fractions from a commercial lemon verbena extract (PLX $\left.{ }^{\circledR} 10\right)$ by semi-preparative chromatography, indicating the major compound(s) identified by HPLC-ESI-TOF-MS, the dry weight of the residue of each fraction and the relative amount taking account the injected quantity. Bold numbers correspond to the peaks with the highest intensity in each isolated fraction.

\begin{tabular}{ccccc}
\hline Fraction & Peak(s) & Major Compound(s) & $\begin{array}{c}\text { Residue Weight } \\
\text { (mg) }\end{array}$ & $\begin{array}{c}\text { Relative Amount } \\
\text { (\%) }\end{array}$ \\
\hline F1 & $\mathbf{1}$ & Shanziside & 0.7 & 2.8 \\
F2 & $\mathbf{2 , 3}$ & Gardoside & 1.0 & 4.0 \\
F3 & $\mathbf{4}$ & Verbasoside & 0.9 & 3.6 \\
F4 & $5, \mathbf{6 , 7 , 8}$ & Cistanoside F isomers & 0.5 & 2.0 \\
F5 & $\mathbf{8}, \mathbf{9}, 10$ & Loganic and epiloganic acids & 0.9 & 3.6 \\
F6 & $\mathbf{1 1}$ & Shanziside methyl ester & 0.6 & 2.4 \\
F7 & $\mathbf{1 2}$ & Theveside & 0.6 & 2.4 \\
F8 & $13,14,16, \mathbf{1 7}$ & Tuberonic acid glucoside + UK & 0.6 & 2.4 \\
F9 & $\mathbf{1 7}, 18,19$ & UK & 0.4 & 1.6 \\
F10 & $17, \mathbf{1 8 , 1 9}$ & B-hydroxy(iso)verbascoside & 0.4 & 1.6 \\
F11 & $\mathbf{2 0}$ & Luteolin-7-diglucuronide & 0.5 & 2.0 \\
F12 & $\mathbf{2 0 , 2 1}$ & Luteolin-7-diglucuronide & 0.2 & 0.8 \\
F13 & 22,26, A & Verbascoside & 2.3 & 9.2 \\
F14 & $\mathbf{2 4 , 2 5}$ & Chrysoeriol-7-diglucuronide & 0.9 & 3.6 \\
F15 & $\mathbf{2 6 , ~ A ~}$ & Isoverbascoside & 1.1 & 4.4 \\
F16 & $\mathbf{A}, 27,28$ & Forsythoside A & 0.7 & 2.8 \\
F17 & $\mathbf{2 9}$ & Acacetin-7-diglucuronide & 0.4 & 1.6 \\
F18 & $\mathbf{3 0 , B}$ & Martynoside & 0.7 & 2.8 \\
F19 & B, C & Osmanthuside B & 0.3 & 1.2 \\
\hline
\end{tabular}




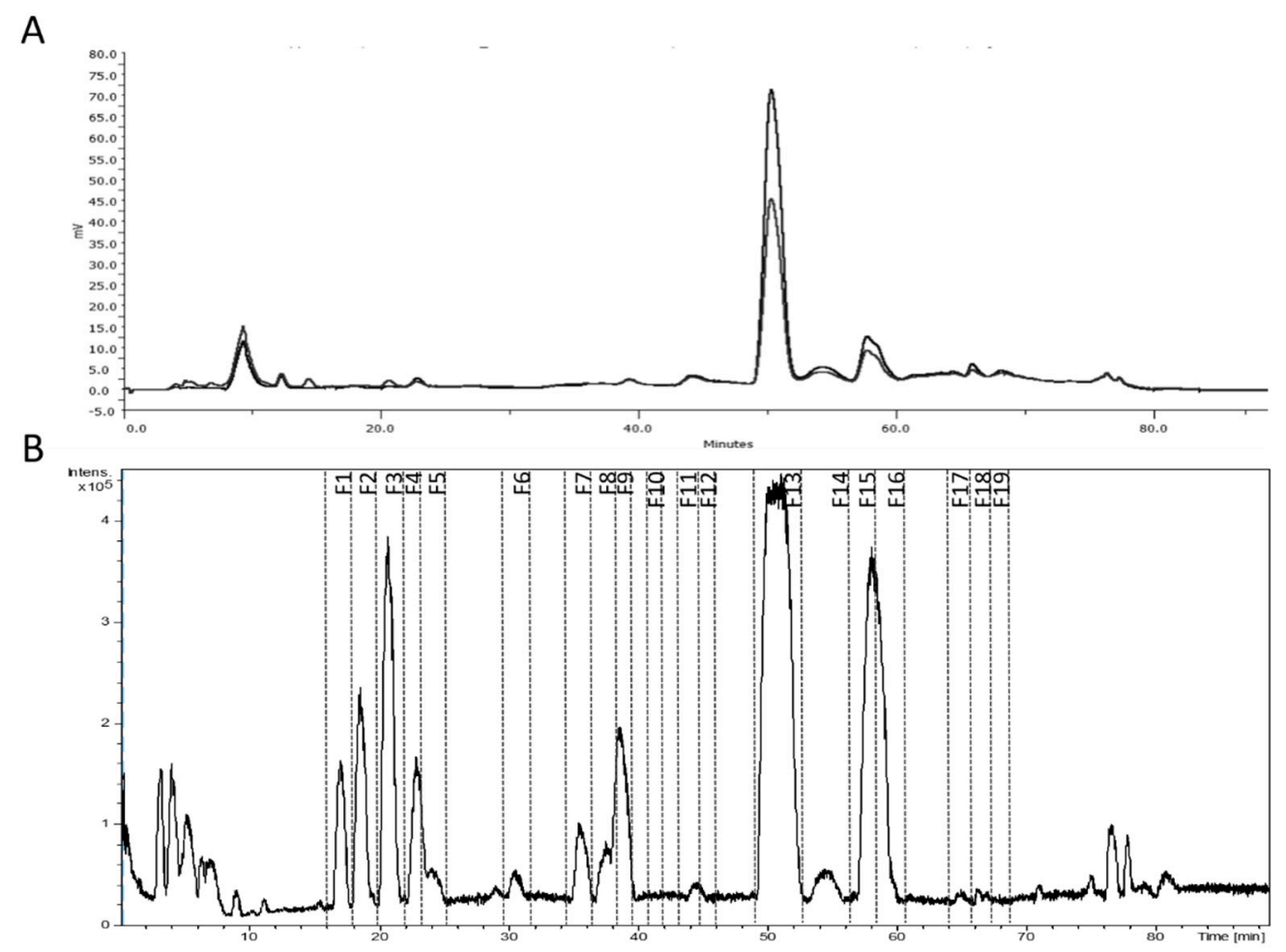

Figure 3. (A) UV chromatogram (240 and $280 \mathrm{~nm}$ ) obtained by the semi-preparative HPLC system and (B) base peak chromatogram monitored by the ESI-TOF mass spectrometer, indicating the collected fractions from the commercial lemon verbena extract (PLX $\left.{ }^{\circledR} 10\right)$.

Three new compounds were detected only in isolated fractions due to their low concentration in the whole extract (Table 3). A new isomer of verbascoside, forsythoside A ( $\mathrm{m} / \mathrm{z} 623)$, was tentatively identified in fractions F13 and F15. Forsythoside A has been found in other L. citriodora extracts [17,38].

Fraction F18 contained not only martynoside but also another compound with the same $\mathrm{m} / z$ value. This peak was tentatively characterized as isomartynoside $(\mathrm{m} / \mathrm{z} 651)$ as occurs in other L. citriodora work [50]. The presence of this compound in botanicals from the lamial species has been corroborated using NMR [51,52]. Isomartynoside was also detected in F19 where a third new compound was found. It was tentatively proposed as osmanthuside B $(m / z 591)$ as it has been reported in a recent study [37]. 
Table 3. Retention time (RT) and mass spectral data of the compounds characterized only in fractions from the commercial lemon verbena extract (PLX $\left.{ }^{\circledR} 10\right)$ by RP-HPLC-ESI-TOF-MS in negative mode.

\begin{tabular}{|c|c|c|c|c|c|c|c|c|c|}
\hline Peak & $\begin{array}{l}\mathrm{RT} \\
(\mathrm{min})\end{array}$ & $\begin{array}{l}{[\mathrm{M}-\mathrm{H}]-} \\
\text { Measured }\end{array}$ & $\begin{array}{l}{[\mathrm{M}-\mathrm{H}]-} \\
\text { Calculated }\end{array}$ & $\begin{array}{l}\text { Error } \\
(\mathrm{ppm})\end{array}$ & mSigma & $\begin{array}{l}\text { Molecular } \\
\text { Formula }\end{array}$ & $\begin{array}{l}\text { Proposed } \\
\text { Compound }\end{array}$ & Reference & Matrix \\
\hline A & 49.84 & 623.1986 & 623.1981 & -0.7 & 4.3 & C 29 H 35 O 15 & Forsythoside A & {$[17,38]$} & L. citriodora \\
\hline B & 56.59 & 651.2292 & 651.2294 & 0.3 & 5.1 & C $31 \mathrm{H} 40 \mathrm{O} 15$ & Isomartynoside & [50-52] & $\begin{array}{c}\text { L. citriodora, } P \text {. } \\
\text { carruthersii, S. tetradonta }\end{array}$ \\
\hline $\mathrm{C}$ & 58.03 & 591.1972 & 591.2083 & 18.9 & 5.6 & С 29 H 36 O 13 & Osmanthuside B & [37] & L. citriodora, C. tubulosa \\
\hline
\end{tabular}




\subsection{Antioxidant Evaluation and Structure-Activity Relationships (SAR) of the Isolated Compounds}

The antioxidant potential of natural extracts has attracted increased scientific interest due to its relationship with the prevention of chronic diseases. Nevertheless, the literature has reported a minor number of studies elucidating the antioxidant power of isolated compounds because of the necessary effort to obtain some of them.

In this context, three different in vitro methods were performed to explore the antioxidant capacity of the isolated compounds from lemon verbena and to establish structure-activity relationships (SAR). To the best of our knowledge, this is the first time that individual antioxidant activity of isolated compounds from lemon verbena has been tested. In addition, the antioxidant potential showed by the fractions was contrasted with the antioxidant activity of the whole extract.

Regarding SET-based methods, the values for the whole lemon verbena extract were $0.676 \pm 0.002 \mathrm{mmol} \mathrm{FE} / \mathrm{g}$ in FRAP assay and $0.35 \pm 0.03 \mathrm{mmol} \mathrm{TE} / \mathrm{g}$ in TEAC assay (Figure 4 and Supplementary Table S1). Concerning isolated fractions, the FRAP values ranged from $0.009 \pm 0.001$ to $1.9 \pm 0.1 \mathrm{mmol} \mathrm{FE} / \mathrm{g}$, while TEAC values were comprised from $0.008 \pm 0.001$ to $0.84 \pm 0.04 \mathrm{mmol} \mathrm{TE} / \mathrm{g}$. In both assays, fraction F13 showed the highest antioxidant potential followed by F15, with greater values that those exhibited by the whole extract. Based on these experimental data, it could be hypothesized that verbascoside and isoverbascoside are the main responsible compounds of the antioxidant effects evidenced by lemon verbena extracts. In contrast, F1 exerted the minor antioxidant capacity and low values were obtained for F2 and F7 in both assays.

\begin{tabular}{|c|c|c|c|c|c|c|c|c|}
\hline \multicolumn{3}{|c|}{ FRAP $^{a}$} & \multicolumn{3}{|c|}{ TEAC $^{b}$} & \multicolumn{3}{|c|}{ ORAC $^{b}$} \\
\hline Sample & $\begin{array}{c}\text { Family major } \\
\text { compound }\end{array}$ & $\mathrm{mmol} \mathrm{FE} / \mathrm{g}$ & Sample & $\begin{array}{c}\text { Family major } \\
\text { compound }\end{array}$ & $\mathrm{mmol} \mathrm{TE} / \mathrm{g}$ & Sample & $\begin{array}{c}\text { Family major } \\
\text { compound }\end{array}$ & $\mathrm{mmol} \mathrm{TE} / \mathrm{g}$ \\
\hline F13 & $\mathrm{PH}$ & 1.86 & F13 & $\mathrm{PH}$ & 0.84 & F13 & $\mathrm{PH}$ & 3.16 \\
\hline F15 & PH & 1.57 & F15 & PH & 0.72 & F12 & $\mathrm{FL}+\mathrm{LI}$ & 1.74 \\
\hline F16 & PH & 0.76 & F16 & PH & 0.37 & F15 & $\mathrm{PH}$ & 1.52 \\
\hline PLX10 & - (EXT) & 0.68 & PLX10 & - (EXT) & 0.35 & PLX10 & - (EXT) & 1.16 \\
\hline F11 & FL & 0.58 & F12 & $F L+L I$ & 0.29 & F11 & FL & 1.15 \\
\hline F12 & $\mathrm{FL}+\mathrm{LI}$ & 0.51 & F11 & FL & 0.25 & F14 & FL & 1.05 \\
\hline F10 & PH & 0.27 & F3 & PH & 0.18 & F3 & PH & 0.99 \\
\hline F3 & PH & 0.27 & F10 & PH & 0.16 & F16 & PH & 0.68 \\
\hline F9 & - (UK) & 0.19 & F9 & - (UK) & 0.11 & F10 & $\mathrm{PH}$ & 0.55 \\
\hline F18 & PH & 0.18 & F18 & PH & 0.10 & F4 & PH & 0.30 \\
\hline F8 & MO & 0.14 & F4 & PH & 0.08 & F9 & - (UK) & 0.29 \\
\hline F4 & $\mathrm{PH}$ & 0.12 & F17 & FL & 0.08 & F18 & PH & 0.23 \\
\hline F17 & FL & 0.12 & F8 & MO & 0.08 & F8 & MO & 0.23 \\
\hline F19 & PH & 0.09 & F14 & FL & 0.06 & F6 & IR & 0.22 \\
\hline F14 & FL & 0.08 & F19 & PH & 0.05 & F5 & IR & 0.19 \\
\hline F6 & IR & 0.07 & F5 & IR & 0.04 & F2 & IR & 0.17 \\
\hline F5 & IR & 0.07 & F6 & IR & 0.04 & F17 & FL & 0.17 \\
\hline F7 & IR & 0.05 & F2 & IR & 0.04 & F19 & PH & 0.14 \\
\hline F2 & IR & 0.05 & F7 & IR & 0.03 & F7 & IR & 0.13 \\
\hline F1 & IR & 0.01 & F1 & IR & 0.01 & F1 & IR & 0.05 \\
\hline
\end{tabular}

Figure 4. In vitro antioxidant activity estimated through ferric ion reducing antioxidant power (FRAP), trolox equivalent antioxidant capacity (TEAC), and oxygen radical absorbance capacity (ORAC) assays for the lemon verbena extract $\left(P L X{ }^{\circledR} 10\right)$ and its collected fractions. Samples were indicated in decreasing order of activity for each assessed method including gradient data bars as graphical representation. ${ }^{a}$ mmoles equivalents of $\mathrm{Fe}^{2+/} \mathrm{g}$ (dry weight), ${ }^{\mathrm{b}}$ mmoles equivalents de Trolox/g (dry weight), EXT: extract, FL: flavonoid, IR: iridoid, LI: lignan, MO: monoterpenoid, PH: phenylpropanoid, UK: unknown.

On the other hand, an ORAC assay was performed as the hydrogen-atom transfer based method and the whole extract showed an antioxidant activity of $1.2 \pm 0.1 \mathrm{mmol} \mathrm{TE} / \mathrm{g}$. With regard to isolated 
fractions, the ORAC values varied from $0.051 \pm 0.008$ to $3.2 \pm 0.3 \mathrm{mmol}$ TE/g. Fraction F13 exhibited the strongest antioxidant power, as occurs in FRAP and TEAC assays but, in this case, was followed by F12. These two fractions and also F15 showed higher values than the whole extract. This reveals that luteolin-7-diglucuronide could play a relevant role in the antioxidant effects of lemon verbena as well. The lowest value was exhibited by F1 and fraction F7 exerted a weak antioxidant potential.

The evaluation of the antioxidant activity of the whole lemon verbena extract allowed its comparison with the literature. Arthur et al. evidenced that the FRAP value varies from $0.17 \pm 0.05$ to $0.73 \pm 0.17 \mathrm{mmol} \mathrm{FE} / \mathrm{g}$ depending on the part of the plant [53]. The FRAP value estimated in the present work is within that range. Furthermore, a lemon verbena extract containing $25 \%$ verbascoside showed a TEAC value 2.5 -fold higher than our result, that is consistent with the $10 \%$ verbascoside in our extract. Concerning an ORAC assay, Buchwald-Werner et al. reported an antioxidant activity of $1.7 \mathrm{mmol} \mathrm{TE} / \mathrm{g}$ using a commercial extract whose verbascoside content was not declared [54].

\subsubsection{Iridoids}

This subclass of monoterpenoids possesses a six-membered ring, containing an oxygen atom, which is combined to a cyclopentane to form the iridane skeleton. Fractions containing an iridoid as major compound (F1, F2, F5, F6, F7) showed the lowest values in SET based methods. Some authors have demonstrated the weak antioxidant power of iridoids with respect to other families of phytocompounds concerning the SET mechanism $[55,56]$. It could be due to the absence of aromatic rings that allow electronic delocalization after losing an electron.

Among these fractions, F5 and F6 exhibited the highest values which were similar between them, while F2 and F7 showed similar weaker values and F1 exerted an insignificant antioxidant activity. Considering their common basic structure, the iridane skeleton, an iridoid could be partial or totally inactive with minor chemical modifications. It has been evidenced that antioxidant activity of iridoids do not improve with more hydroxyl groups $(-\mathrm{OH})$, as occurs in polyphenols [57]. Loganic and epiloganic acids (F5) present one hydroxyl group less than shanziside (F1) and exhibited higher activity (Figure 5A). Nevertheless, shanziside esterification with a methyl group (F6) lead the strongest activity in the FRAP assay. Gardoside (F2) and theveside (F7) differs to shanziside with other substitutions and exerted higher antioxidant power.

Concerning the ORAC assay, it should be noted that the antioxidant power of fraction F2 was slightly higher than that exhibited by F7. The presence of ixoside in F2 could have contributed to the observed effect. This compound presents an additional carboxyl group $(-\mathrm{COOH})$ where hydrogen atom is more reactive because of the carbonyl group $(-\mathrm{C}=\mathrm{O})$. However, the ability of fractions containing iridoids to reduce peroxyl radicals transferring a hydrogen atom was generally low in this assay. It could be due to the absence of aromatic rings that stabilize the resulting oxidized compound. Indeed, iridoids did not show a good hydrogen-donating ability in other studies $[35,58]$.

\subsubsection{Glycosylated Phenylpropanoids}

Phenylpropanoids belong to the phenolic compounds family which possess aromatic rings, giving more stable radical forms than other compounds after their oxidation. The influence of hydroxyl groups on the antioxidant capacity of other phenolic groups have been documented but, to our knowledge, this is the first study to establish SAR in phenylpropanoids. It was recognized that the catechol (ortho-dihydroxybenzene) unit is the main responsible structure in strong antioxidant phenolic compounds [59]. Fractions including glycosylated phenylpropanoids (F3, F4, F10, F13, F15, F16, F18, and F19) exhibited similar antioxidant power in FRAP and TEAC assays.

Fraction F13, corresponding to verbascoside, showed the strongest activity followed by F15 and F16 which presented its isomers isoverbascoside and forsythoside A, respectively. These three compounds are position isomers with two catechol units, one from each part connected to the glycosidic portion which are equal to hydroxytyrosol and caffeic acid (Figure 5B). Some authors have reported 
the higher antioxidant activity of verbascoside than that of isoverbascoside, reflecting the influence of the caffeoyl moiety position $[60,61]$.

A
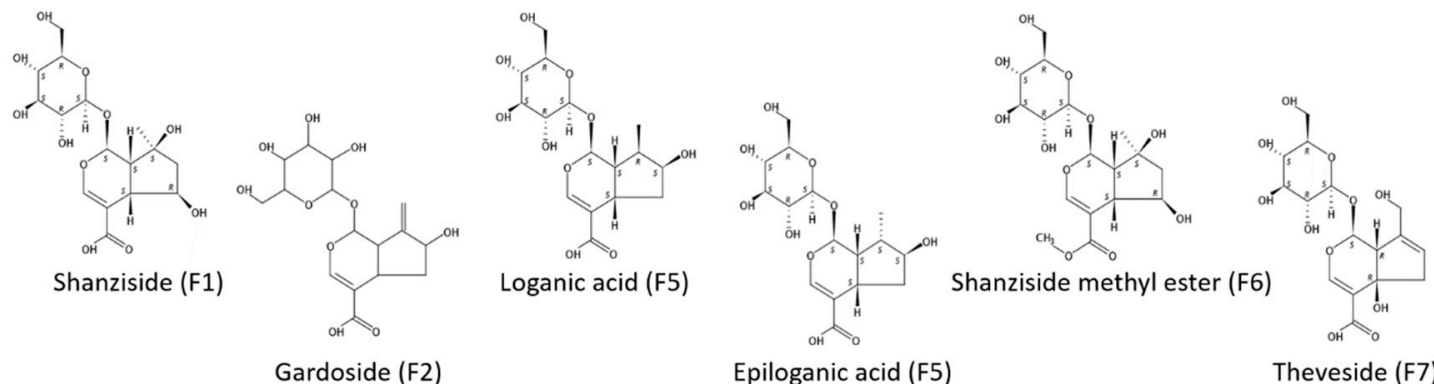

Epiloganic acid (F5)

Theveside (F7)

B

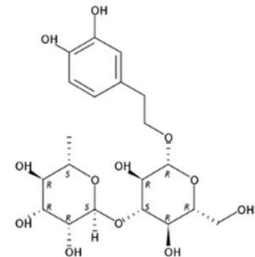

Verbasoside (F3)

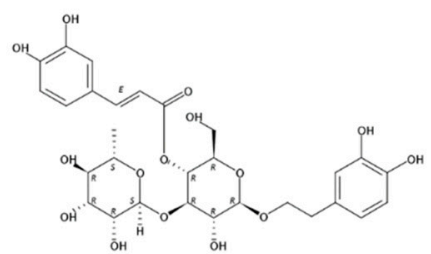

Verbascoside (F13)

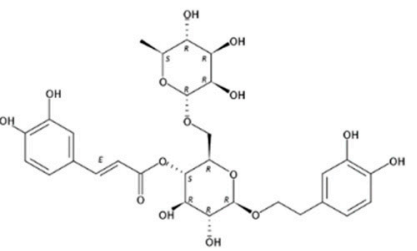

Forsythoside A (F16)

C

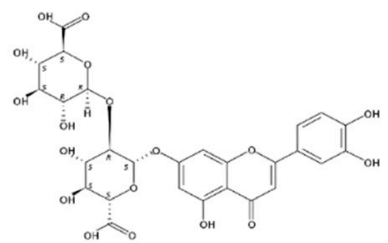

Luteolin-7-diglucuronide (F11, F12)

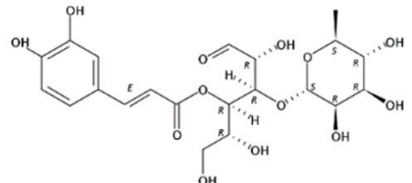

Cistanoside F (F4)

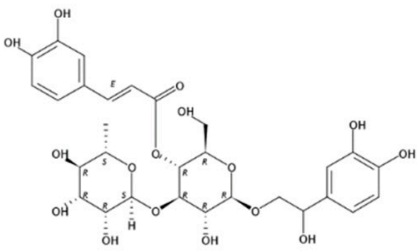

$\beta$-hydroxyverbascoside (F10)

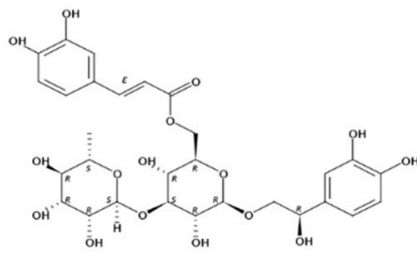

$\beta$-hydroxyisoverbascoside (F10)

Isoverbascoside (F15)

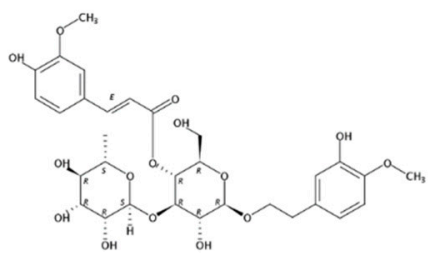

Martynoside (F18)

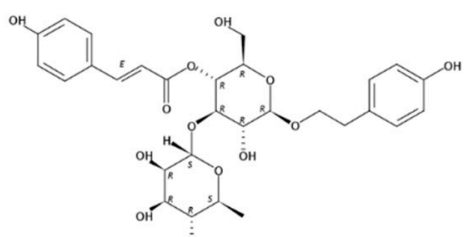

Osmanthuside B (F19)

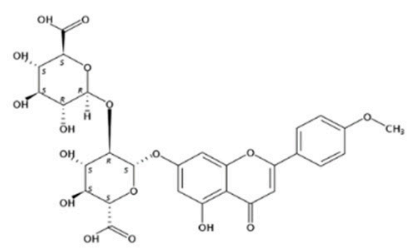

Acacetin-7-diglucuronide (F17)
D

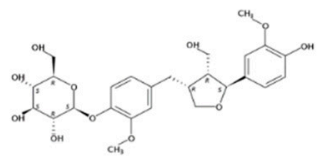

Lariciresinol-4-O- $\beta$-D-glucopyranoside (F12)
$E$

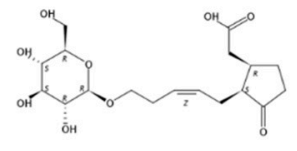

Tuberonic acid glucoside (F8)

Figure 5. Chemical structures of the major compounds from the fractions classified in (A) iridoids, (B) glycosylated phenylpropanoids, (C) flavonoids, (D) lignan, and (E) monoterpenoid. 
Verbasoside (F3) and $\beta$-hydroxyverbascoside together with $\beta$-hydroxyisoverbascoside (F10) exerted similar lower values. Verbasoside has one catechol unit so that its minor antioxidant activity is consistent. The extra hydroxylation in $\beta$-hydroxy(iso)verbascoside compared to (iso)verbascoside transform its phenylpropanoid part in a 3-4-dihydroxyphenylglycol moiety. There has been evidence of the stronger antioxidant activity of hydroxytyrosol than that exhibited by 3-4-dihydroxyphenylglycol [62].

Furthermore, F18 containing martynoside and isomartynoside showed a weaker antioxidant activity in both SET-based methods. There is not any catechol unit in these compounds where a hydroxyl group from each aromatic ring is etherified with a methyl group, forming a methoxy-phenylethanoid portion and a ferulic moiety. Ferulic acid has exhibited a lower antioxidant potential than caffeic acid in another study [63]. The major contribution of cistanoside F isomers in F4 lead to a lower antioxidant capacity of this fraction. Cistanoside F possesses only one phenolic ring in a caffeoyl moiety. The presence of two aromatic rings in (iso)martynoside could explain the higher activity of F18 than that of F4 in despite of the presence of caffeoyl moiety in cistanoside F. Nevertheless, it is worth to clarify the difference between this last compound and verbasoside: Both compounds present a catechol unit, but it is equal to hydroxytyrosol in verbasoside. The stronger antioxidant power of hydroxytyrosol compared to caffeic acid has been demonstrated [64]. Osmanthuside B (F19) possesses two monohydroxylated aromatic rings and exerts the lowest antioxidant power, corroborating the influence of the catechol group.

With respect to the ORAC results, there are some values that should be highlighted. Verbascoside (F13) showed the most powerful antioxidant effect with a value 2-fold higher than the estimated for isoverbascoside (F15), which in turn was 2-fold higher than that of forsythoside A (F16). Thus, the influence of the position of the caffeoyl group in verbascoside isomers was more notable for their capacity to transfer a hydrogen atom. Moreover, verbasoside (F3) exhibited a stronger antioxidant activity than of forsythoside A.

In contrast to SET-based methods, fraction F4 containing cistanoside F exerted a higher ORAC value than F18. In this case, the two hydroxyl groups in ortho position from the catechol unit could allow the formation of two hydrogen bonds with the two oxygen atoms of the peroxyl radical. This fact leads to a very compact reactant complex where the hydrogen abstraction would be more favorable as the quantum-mechanical tunneling explains [65].

\subsubsection{Flavonoids}

Among the obtained fractions, four of them (F11, F12, F14, F17) presented a flavonoid as the major compound that belong to the flavones subgroup. Luteolin-7-diglucuronide was contained in fractions F11 and F12, but the determination of the composition of each fraction by HPLC-ESI-TOF-MS revealed the minor presence of lariciresinol-4-O- $\beta$-D-glucopyranoside in F12 and its contribution in the antioxidant effect was subject to study.

The SAR of the antioxidant potential of flavonoids was established by Rice-Evans et al. [63]. It is closely associated with the substitution with hydroxyl groups as occurs in other phenolic compounds, but the complexity of the flavonoid structure should be considered. Briefly, the radical-scavenging capacity is notably increased with a catechol unit in the B ring. A C2-C3 double bond configured with a 4-keto arrangement in the $C$ ring, as is present in flavones, facilitates the electron delocalization from the $\mathrm{B}$ ring.

In SET-based methods, F11 and F12 showed the highest antioxidant activity. It was very similar between them and slightly lower than the exhibited by the whole extract. This is consistent with the luteolin-7-diglucuronide structure which possess the catechol unit in the B ring (Figure 5C). Estimated values for fraction F17 were 4-fold and 3-fold lower than F11/F12 in FRAP and TEAC assays, respectively. This fraction contained acacetin-7-diglucuronide where is a methoxy group in the B ring, so that the absence of the catechol group justifies the decreased antioxidant power. Chrysoeriol-7-diglucuronide (F14) exerted the lowest antioxidant power, but there were not large differences with F17. 
Concerning the ORAC assay, it is worth remarking on the higher value determined for F12 than that of F11. In this case, lariciresinol-4-O- $\beta$-D-glucopyranoside seems to have a significant ability to scavenge peroxyl radicals transferring a hydrogen atom (Figure 5D). Furthermore, chrysoeriol-7-diglucuronide (F14) showed a higher antioxidant activity than acacetin-7-diglucuronide (F17). This is consistent with the absence of any hydroxyl group in the B ring of the last compound.

\subsubsection{Other Compounds}

The remaining fractions (F8 and F9) exhibited a moderated antioxidant activity compared to other fractions. Fraction F8 was composed of tuberonic acid glucoside isomers and UK, while F9 contained UK, $\beta$-hydroxyverbascoside, and $\beta$-hydroxyisoverbascoside.

In all assays (FRAP, TEAC, and ORAC), F9 exerted a stronger antioxidant power than of F8. Ruberto and Barata analyzed the antioxidant activity of 100 terpenoids to establish SAR in this family of compounds [66]. In their study, it is related that the antioxidant potential of monoterpenoids tends to be higher with oxygenated substitutions in the following order: Phenol $>$ allylic alcohol $>$ aldehyde and ketone. Tuberonic acid is the 12-hydroxilated derivative of jasmonic acid which presents a keto group and a carboxyl group, so that it could have certain antioxidant activity (Figure 5E). Nevertheless, regarding the analytical composition of both fractions, UK seems to be the main contributor in the determined antioxidant activity for $\mathrm{F} 8$ that would be increased by $\beta$-hydroxyverbascoside and $\beta$-hydroxyisoverbascoside in F9. It is necessary to elucidate the chemical structure of UK to entirely establish the SAR for these compounds.

\section{Conclusions}

In the present work, a total of 30 compounds were identified in a commercial lemon extract by HPLC-ESI-TOF-MS previous to its fractionation by semi-preparative chromatography. The same powerful analytical technique was employed for analyzing the composition of the 19 fractions that were obtained and three new compounds were characterized. Afterwards, the antioxidant activity of the fractions was explored, and the SAR was established for the isolated compounds which were mainly iridoids, glycosylated phenylpropanoids, and flavonoids.

In conclusion, phenolic compounds exerted the strongest antioxidant power, as was expected. The presence of the catechol unit in those compounds is decisive, while our results demonstrated that hydroxyl groups are not fundamental in the iridoids subgroup of monoterpenoids. Nevertheless, fractions containing compounds from this last subgroup did not show an interesting antioxidant activity. Generally, the strongest antioxidant activity was exhibited by phenylpropanoids and, as far as we know, this is the first study where their SAR was explored. The influence of the position of the caffeoyl moiety in verbascoside and its isomers has been evidenced in our study and could be considered in the design and development of future bioactive compounds recovering processes. Moreover, verbasoside and $\beta$-hydroxy(iso)verbascoside showed an interesting antioxidant potential. Luteolin-7-diglucuronide exhibited the highest antioxidant potential among the studied flavonoids in all assays. The development of enriched extracts in these mentioned compounds, not only in verbascoside, could lead to greater antioxidant effects and improved functional ingredients for the prevention of chronic diseases.

Supplementary Materials: The following are available online at http://www.mdpi.com/2076-3921/8/8/324/s1, Figure S1. UV chromatograms at $280 \mathrm{~nm}$ and MS spectra for (A) peak 5 and (B) peak 28; Figure S2. Base peak chromatograms of the collected fractions from a commercial lemon verbena extract (PLX $\left.{ }^{\circledR} 10\right)$ and MS spectra of their major compound, including the peak numbers of Table 1; Table S1. In vitro antioxidant activity by FRAP, TEAC and ORAC assays for the commercial lemon verbena extract (PLX $\left.{ }^{\circledR} 10\right)$ and its collected fractions, expressed as the mean of three independent replicates \pm the standard deviation.

Author Contributions: Conceptualization, J.L.-S. and A.S.-C.; Funding acquisition, A.S.-C. and V.M; Investigation, N.S.-M.; Methodology, N.S.-M., J.L.-S., M.H.-L, and M.d.l.L.C.-G.; Project administration, A.S.-C.; Supervision, J.L.-S. and A.S.-C.; Writing - original draft, N.S.-M.; Writing - review \& editing, J.L.-S. and A.S.-C. 
Funding: This work was funded by projects AGL2015-67995-C3-2-R, RTI2018-096724-B-C21 and RTI2018-096724B-C22 from Spanish Ministry of Economy and Competitiveness and P11-CTS-7625 from Andalusian Regional Government Council of Innovation and Science. We also thank projects and scholarships from the Generalitat Valenciana (PROMETEO/2016/006, ACIF/2016/230 and APOSTD/2017/023) and grant from CIBER (CB12/03/30038, Fisiopatologia de la Obesidad y la Nutricion, CIBERobn, Instituto de Salud Carlos III).

Conflicts of Interest: The authors declare no conflict of interest.

\section{References}

1. Elechosa, M.A.; Di Leo Lira, P.; Juarez, M.A.; Viturro, C.I.; Heit, C.I.; Molina, A.C.; Martínez, A.J.; Lopez, S.; Molina, A.M.; van Baren, C.M.; et al. Essential oil chemotypes of Aloysia citrodora (Verbenaceae) in Northwestern Argentina. Biochem. Syst. Ecol. 2017, 74, 19-29. [CrossRef]

2. Bahramsoltani, R.; Rostamiasrabadi, P.; Shahpiri, Z.; Marques, A.M.; Rahimi, R.; Farzaei, M.H. Aloysia citrodora Palau (Lemon verbena): A review of phytochemistry and pharmacology. J. Ethnopharmacol. 2018, 222, 34-51. [CrossRef] [PubMed]

3. Lenoir, L.; Joubert-Zakeyh, J.; Texier, O.; Lamaison, J.L.; Vasson, M.P.; Felgines, C. Aloysia triphylla infusion protects rats against dextran sulfate sodium-induced colonic damage. J. Sci. Food Agric. 2012, 92, 1570-1572. [CrossRef] [PubMed]

4. Rashidian, A.; Farhang, F.; Vahedi, H.; Dehpour, A.R.; Ejtemai Mehr, S.; Mehrzadi, S.; Rezayat, S.M. Anticonvulsant Effects of Lippia citriodora (Verbenaceae) Leaves Ethanolic Extract in Mice: Role of GABAergic System. Int. J. Prev. Med. 2016, 7, 97. [CrossRef] [PubMed]

5. Mestre-Alfaro, A.; Ferrer, M.D.; Sureda, A.; Tauler, P.; Martinez, E.; Bibiloni, M.M.; Micol, V.; Tur, J.A.; Pons, A. Phytoestrogens enhance antioxidant enzymes after swimming exercise and modulate sex hormone plasma levels in female swimmers. Eur. J. Appl. Physiol. 2011, 111, 2281-2294. [CrossRef] [PubMed]

6. Carrera-Quintanar, L.; Funes, L.; Vicente-Salar, N.; Blasco-Lafarga, C.; Pons, A.; Micol, V.; Roche, E. Effect of polyphenol supplements on redox status of blood cells: A randomized controlled exercise training trial. Eur. J. Nutr. 2015, 54, 1081-1093. [CrossRef] [PubMed]

7. Carrera-Quintanar, L.; Funes, L.; Viudes, E.; Tur, J.; Micol, V.; Roche, E.; Pons, A. Antioxidant effect of lemon verbena extracts in lymphocytes of university students performing aerobic training program. Scand. J. Med. Sci. Sports 2012, 22, 454-461. [CrossRef]

8. Funes, L.; Fernández-Arroyo, S.; Laporta, O.; Pons, A.; Roche, E.; Segura-Carretero, A.; Fernández-Gutierrez, A.; Micol, V. Correlation between plasma antioxidant capacity and verbascoside levels in rats after oral administration of lemon verbena extract. Food Chem. 2009, 117, 589-598. [CrossRef]

9. Malekirad, A.A.; Hosseini, N.; Bayrami, M.; Hashemi, T.; Rahzani, K.; Abdollahi, M. Benefit of lemon verbena in healthy subjects; targeting diseases associated with oxidative stress. Asian J. Anim. Vet. Adv. 2011, 6, 953-957. [CrossRef]

10. Mauriz, E.; Vallejo, D.; Tunon, M.J.; Rodriguez-Lopez, J.M.; Rodriguez-Perez, R.; Sanz-Gomez, J.; Garcia-Fernandez Mdel, C. Effects of dietary supplementation with lemon verbena extracts on serum inflammatory markers of multiple sclerosis patients. Nutr. Hosp. 2014, 31, 764-771. [CrossRef]

11. Campo, G.; Pavasini, R.; Biscaglia, S.; Ferri, A.; Andrenacci, E.; Tebaldi, M.; Ferrari, R. Platelet aggregation values in patients with cardiovascular risk factors are reduced by verbascoside treatment. A randomized study. Pharmacol. Res. 2015, 97, 1-6. [CrossRef] [PubMed]

12. Caturla, N.; Funes, L.; Perez-Fons, L.; Micol, V. A randomized, double-blinded, placebo-controlled study of the effect of a combination of lemon verbena extract and fish oil omega-3 fatty acid on joint management. J. Altern. Complement. Med. 2011, 17, 1051-1063. [CrossRef] [PubMed]

13. Hohn, A.; Konig, J.; Grune, T. Protein oxidation in aging and the removal of oxidized proteins. J. Proteom. 2013, 92, 132-159. [CrossRef]

14. Brem, R.; Guven, M.; Karran, P. Oxidatively-generated damage to DNA and proteins mediated by photosensitized UVA. Free Radic. Biol. Med. 2017, 107, 101-109. [CrossRef] [PubMed]

15. De Carvalho, F.O.; Felipe, F.A.; de Melo Costa, A.C.; Teixeira, L.G.; Silva, E.R.; Nunes, P.S.; Shanmugam, S.; de Lucca Junior, W.; Quintans, J.S.; de Souza Araujo, A.A. Inflammatory Mediators and Oxidative Stress in Animals Subjected to Smoke Inhalation: A Systematic Review. Lung 2016, 194, 487-499. [CrossRef] [PubMed] 
16. Herranz-Lopez, M.; Barrajon-Catalan, E.; Segura-Carretero, A.; Menendez, J.A.; Joven, J.; Micol, V. Lemon verbena (Lippia citriodora) polyphenols alleviate obesity-related disturbances in hypertrophic adipocytes through AMPK-dependent mechanisms. Phytomedicine 2015, 22, 605-614. [CrossRef] [PubMed]

17. Quirantes-Pine, R.; Funes, L.; Micol, V.; Segura-Carretero, A.; Fernandez-Gutierrez, A. High-performance liquid chromatography with diode array detection coupled to electrospray time-of-flight and ion-trap tandem mass spectrometry to identify phenolic compounds from a lemon verbena extract. J. Chromatogr. A 2009, 1216, 5391-5397. [CrossRef] [PubMed]

18. Argyropoulou, C.; Daferera, D.; Tarantilis, P.A.; Fasseas, C.; Polissiou, M. Chemical composition of the essential oil from leaves of Lippia citriodora H.B.K. (Verbenaceae) at two developmental stages. Biochem. Syst. Ecol. 2007, 35, 831-837. [CrossRef]

19. Parodi, T.V.; Vargas, A.P.D.C.; Krewer, C.; De Moraes Flores, E.M.; Baldisserotto, B.; Heinzmann, B.M.; De Oliveira, J.V.; Popiolski, A.S.; Minozzo, M. Chemical composition and antibacterial activity of Aloysia triphylla (L'Hérit) Britton extracts obtained by pressurized CO2 extraction. Braz. Arch. Biol. Technol. 2013, 56, 283-292. [CrossRef]

20. Martino, N.A.; Ariu, F.; Bebbere, D.; Uranio, M.F.; Chirico, A.; Marzano, G.; Sardanelli, A.M.; Cardinali, A.; Minervini, F.; Bogliolo, L.; et al. Supplementation with nanomolar concentrations of verbascoside during in vitro maturation improves embryo development by protecting the oocyte against oxidative stress: A large animal model study. Reprod. Toxicol. 2016, 65, 204-211. [CrossRef]

21. Mosca, M.; Ambrosone, L.; Semeraro, F.; Casamassima, D.; Vizzarri, F.; Costagliola, C. Ocular tissues and fluids oxidative stress in hares fed on verbascoside supplement. Int. J. Food Sci. Nutr. 2014, 65, 235-240. [CrossRef] [PubMed]

22. Vertuani, S.; Beghelli, E.; Scalambra, E.; Malisardi, G.; Copetti, S.; Dal Toso, R.; Baldisserotto, A.; Manfredini, S. Activity and stability studies of verbascoside, a novel antioxidant, in dermo-cosmetic and pharmaceutical topical formulations. Molecules 2011, 16, 7068-7080. [CrossRef] [PubMed]

23. Cádiz-Gurrea, M.L.; Lozano-Sanchez, J.; Contreras-Gámez, M.; Legeai-Mallet, L.; Fernández-Arroyo, S.; Segura-Carretero, A. Isolation, comprehensive characterization and antioxidant activities of Theobroma cacao extract. J. Funct. Foods 2014, 10, 485-498. [CrossRef]

24. Quirantes-Pine, R.; Lozano-Sanchez, J.; Herrero, M.; Ibanez, E.; Segura-Carretero, A.; Fernandez-Gutierrez, A. HPLC-ESI-QTOF-MS as a powerful analytical tool for characterising phenolic compounds in olive-leaf extracts. Phytochem. Anal. 2013, 24, 213-223. [CrossRef] [PubMed]

25. Abu-Reidah, I.M.; Arraez-Roman, D.; Lozano-Sanchez, J.; Segura-Carretero, A.; Fernandez-Gutierrez, A. Phytochemical characterisation of green beans (Phaseolus vulgaris L.) by using high-performance liquid chromatography coupled with time-of-flight mass spectrometry. Phytochem. Anal. 2013, 24, 105-116. [CrossRef]

26. Morales-Soto, A.; García-Salas, P.; Rodríguez-Pérez, C.; Jiménez-Sánchez, C.; Cádiz-Gurrea, M.L.; Segura-Carretero, A.; Fernández-Gutiérrez, A. Antioxidant capacity of 44 cultivars of fruits and vegetables grown in Andalusia (Spain). Food Res. Int. 2014, 58, 35-46. [CrossRef]

27. Bringmann, G.; Kajahn, I.; Neususs, C.; Pelzing, M.; Laug, S.; Unger, M.; Holzgrabe, U. Analysis of the glucosinolate pattern of Arabidopsis thaliana seeds by capillary zone electrophoresis coupled to electrospray ionization-mass spectrometry. Electrophoresis 2005, 26, 1513-1522. [CrossRef]

28. Benzie, I.F.; Strain, J.J. The ferric reducing ability of plasma (FRAP) as a measure of "antioxidant power": The FRAP assay. Anal. Biochem. 1996, 239, 70-76. [CrossRef]

29. Miller, N.J.; Rice-Evans, C.; Davies, M.J.; Gopinathan, V.; Milner, A. A novel method for measuring antioxidant capacity and its application to monitoring the antioxidant status in premature neonates. Clin. Sci. 1993, 84, 407-412. [CrossRef]

30. Cádiz-Gurrea, M.L.; Fernández-Arroyo, S.; Joven, J.; Segura-Carretero, A. Comprehensive characterization by UHPLC-ESI-Q-TOF-MS from an Eryngium bourgatii extract and their antioxidant and anti-inflammatory activities. Food Res. Int. 2013, 50, 197-204. [CrossRef]

31. Ou, B.; Hampsch-Woodill, M.; Prior, R.L. Development and validation of an improved oxygen radical absorbance capacity assay using fluorescein as the fluorescent probe. J. Agric Food Chem. 2001, 49, 4619-4626. [CrossRef] [PubMed]

32. Quirantes-Pine, R.; Arraez-Roman, D.; Segura-Carretero, A.; Fernandez-Gutierrez, A. Characterization of phenolic and other polar compounds in a lemon verbena extract by capillary electrophoresis-electrospray ionization-mass spectrometry. J. Sep. Sci. 2010, 33, 2818-2827. [CrossRef] [PubMed] 
33. Cadiz-Gurrea, M.L.; Olivares-Vicente, M.; Herranz-Lopez, M.; Arraez-Roman, D.; Fernandez-Arroyo, S.; Micol, V.; Segura-Carretero, A. Bioassay-guided purification of Lippia citriodora polyphenols with AMPK modulatory activity. J. Funct. Foods 2018, 46, 514-520. [CrossRef]

34. Rastrelli, L.; Caceres, A.; Morales, C.; De Simone, F.; Aquino, R. Iridoids from Lippia graveolens. Phytochemistry 1998, 49, 1829-1832. [CrossRef]

35. Kucharska, A.Z.; Sokol-Letowska, A.; Oszmianski, J.; Piorecki, N.; Fecka, I. Iridoids, Phenolic Compounds and Antioxidant Activity of Edible Honeysuckle Berries (Lonicera caerulea var. kamtschatica Sevast.). Molecules 2017, 22, 405. [CrossRef] [PubMed]

36. Barbosa, F.G.; Lima, M.A.S.; Braz-Filho, R.; Silveira, E.R. Iridoid and phenylethanoid glycosides from Lippia alba. Biochem. Syst. Ecol. 2006, 34, 819-821. [CrossRef]

37. Leyva-Jimenez, F.J.; Lozano-Sanchez, J.; Borras-Linares, I.; Arraez-Roman, D.; Segura-Carretero, A. Comparative study of conventional and pressurized liquid extraction for recovering bioactive compounds from Lippia citriodora leaves. Food Res. Int. 2018, 109, 213-222. [CrossRef]

38. Ivanovic, M.; Alanon, M.E.; Arraez-Roman, D.; Segura-Carretero, A. Enhanced and green extraction of bioactive compounds from Lippia citriodora by tailor-made natural deep eutectic solvents. Food Res. Int. 2018, 111, 67-76. [CrossRef]

39. Nakamura, T.; Okuyama, E.; Tsukada, A.; Yamazaki, M.; Satake, M.; Nishibe, S.; Nishimura, H. Acteoside as the analgesic principle of Cedron (Lippia triphylla), a Peruvian medicinal plant. Chem. Pharm. Bull. 1997, 45, 499-504. [CrossRef]

40. Timoteo, P.; Karioti, A.; Leitao, S.G.; Vincieri, F.F.; Bilia, A.R. A validated HPLC method for the analysis of herbal teas from three chemotypes of Brazilian Lippia alba. Food Chem. 2015, 175, 366-373. [CrossRef]

41. Koïta, K.; Baissac, Y.; Sanon, E.; Campa, C.; Sankara, P. Phenolics from Lippia multiflora Moldenke as potential bioactive agents against peanut pathogens. Agric. Sci. Res. J. 2017, 7, 267-276.

42. Saidi, I.; Waffo-Teguo, P.; Ayeb-Zakhama, A.E.L.; Harzallah-Skhiri, F.; Marchal, A.; Ben Jannet, H. Phytochemical study of the trunk bark of Citharexylum spinosum L. growing in Tunisia: Isolation and structure elucidation of iridoid glycosides. Phytochemistry 2018, 146, 47-55. [CrossRef] [PubMed]

43. Friscic, M.; Bucar, F.; Hazler Pilepic, K. LC-PDA-ESI-MS(n) analysis of phenolic and iridoid compounds from Globularia spp. J. Mass Spectrom. 2016, 51, 1211-1236. [CrossRef] [PubMed]

44. Anhalt, S.; Weissenbock, G. Subcellular localization of luteolin glucuronides and related enzymes in rye mesophyll. Planta 1992, 187, 83-88. [CrossRef] [PubMed]

45. Funari, C.S.; Eugster, P.J.; Martel, S.; Carrupt, P.A.; Wolfender, J.L.; Silva, D.H. High resolution ultra high pressure liquid chromatography-time-of-flight mass spectrometry dereplication strategy for the metabolite profiling of Brazilian Lippia species. J. Chromatogr. A 2012, 1259, 167-178. [CrossRef] [PubMed]

46. Rungsimakan, S.; Rowan, M.G. Terpenoids, flavonoids and caffeic acid derivatives from Salvia viridis L. cvar. Blue Jeans. Phytochemistry 2014, 108, 177-188. [CrossRef]

47. Mari, A.; Ciocarlan, A.; Aiello, N.; Scartezzini, F.; Pizza, C.; D’Ambrosio, M. Research survey on iridoid and phenylethanoid glycosides among seven populations of Euphrasia rostkoviana Hayne from the Alps. Phytochemistry 2017, 137, 72-80. [CrossRef]

48. Zhou, F.; Zhao, Y.; Li, M.; Xu, T.; Zhang, L.; Lu, B.; Wu, X.; Ge, Z. Degradation of phenylethanoid glycosides in Osmanthus fragrans Lour. flowers and its effect on anti-hypoxia activity. Sci. Rep. 2017, 7, 10068. [CrossRef]

49. Marston, A. Role of advances in chromatographic techniques in phytochemistry. Phytochemistry 2007, 68, 2786-2798. [CrossRef]

50. Ono, M.; Oda, E.; Tanaka, T.; Iida, Y.; Yamasaki, T.; Masuoka, C.; Ikeda, T.; Nohara, T. DPPH radical-scavenging effect on some constituents from the aerial parts of Lippia triphylla. J. Nat. Med. 2008, 62, 101-106. [CrossRef]

51. Vo, T.N.; Nguyen, P.L.; Tuong, L.T.; Vo, P.N.; Nguyen, K.P.P.; Nguyen, N.S. Constituents of the leaves of Pseuderanthemum carruthersii (Seem.) Guill. var. atropurpureum (Bull.) Fosb. Phytochem. Lett. 2012, 5, 673-676. [CrossRef]

52. Dou, H.; Liao, X.; Peng, S.; Pan, Y.; Ding, L. Chemical Constituents from the Roots of Schnabelia tetradonta. Helv. Chim. Acta. 2033, 86, 2711-2936. [CrossRef]

53. Arthur, H.; Joubert, E.; De Beer, D.; Malherbe, C.J.; Witthuhn, R.C. Phenylethanoid glycosides as major antioxidants in Lippia multiflora herbal infusion and their stability during steam pasteurisation of plant material. Food Chem. 2011, 127, 581-588. [CrossRef] [PubMed] 
54. Buchwald-Werner, S.; Naka, I.; Wilhelm, M.; Schutz, E.; Schoen, C.; Reule, C. Effects of lemon verbena extract (Recoverben(R)) supplementation on muscle strength and recovery after exhaustive exercise: A randomized, placebo-controlled trial. J. Int. Soc. Sports Nutr. 2018, 15, 5. [CrossRef] [PubMed]

55. Kirmizibekmez, H.; Ariburnu, E.; Masullo, M.; Festa, M.; Capasso, A.; Yesilada, E.; Piacente, S. Iridoid, phenylethanoid and flavonoid glycosides from Sideritis trojana. Fitoterapia 2012, 83, 130-136. [CrossRef] [PubMed]

56. Lu, Q.; Sun, Y.; Shu, Y.; Tan, S.; Yin, L.; Guo, Y.; Tang, L. HSCCC Separation of the Two Iridoid Glycosides and Three Phenolic Compounds from Veronica ciliata and Their in Vitro Antioxidant and Anti-Hepatocarcinoma Activities. Molecules 2016, 21, 1234. [CrossRef] [PubMed]

57. Gousiadou, C.; Gotfredsen, C.H.; Matsa, M.; Hadjipavlou-Litina, D.; Skaltsa, H. Minor iridoids from Scutellaria albida ssp. albida. Inhibitory potencies on lipoxygenase, linoleic acid lipid peroxidation and antioxidant activity of iridoids from Scutellaria sp. J. Enzym. Inhib. Med. Chem. 2013, 28, 704-710. [CrossRef] [PubMed]

58. Pacifico, S.; D’Abrosca, B.; Pascarella, M.T.; Letizia, M.; Uzzo, P.; Piscopo, V.; Fiorentino, A. Antioxidant efficacy of iridoid and phenylethanoid glycosides from the medicinal plant Teucrium chamaedris in cell-free systems. Bioorg. Med. Chem. 2009, 17, 6173-6179. [CrossRef] [PubMed]

59. Andreasen, M.F.; Landbo, A.K.; Christensen, L.P.; Hansen, A.; Meyer, A.S. Antioxidant effects of phenolic rye (Secale cereale L.) extracts, monomeric hydroxycinnamates, and ferulic acid dehydrodimers on human low-density lipoproteins. J. Agric. Food Chem. 2001, 49, 4090-4096. [CrossRef]

60. Plaza, A.; Montoro, P.; Benavides, A.; Pizza, C.; Piacente, S. Phenylpropanoid glycosides from Tynanthus panurensis: Characterization and LC-MS quantitative analysis. J. Agric. Food Chem. 2005, 53, 2853-2858. [CrossRef]

61. Fuji, Y.; Uchida, A.; Fukahori, K.; Chino, M.; Ohtsuki, T.; Matsufuji, H. Chemical characterization and biological activity in young sesame leaves (Sesamum indicum L.) and changes in iridoid and polyphenol content at different growth stages. PLoS ONE 2018, 13, e0194449. [CrossRef] [PubMed]

62. Allouche, N.; Feki, M.; Damak, M.; Sayadi, S. Isolation of hydroxytyrosol 4-b-D-glucoside and 3,4-dihydroxyphenylglycol with antioxidant activity from olive mill wastewaters. J. Tunis. Chem. Soc. 2005, 7, 2031-2238.

63. Rice-Evans, C.A.; Miller, N.J.; Paganga, G. Antioxidant properties of phenolic compounds. Trends Plant. Sci. 1997, 2, 152-159. [CrossRef]

64. Bouallagui, Z.; Bouaziz, M.; Lassoued, S.; Engasser, J.M.; Ghoul, M.; Sayadi, S. Hydroxytyrosol acyl esters: Biosynthesis and activities. Appl. Biochem. Biotechnol. 2011, 163, 592-599. [CrossRef] [PubMed]

65. Tejero, I.; Gonzalez-Garcia, N.; Gonzalez-Lafont, A.; Lluch, J.M. Tunneling in green tea: Understanding the antioxidant activity of catechol-containing compounds. A variational transition-state theory study. J. Am. Chem. Soc. 2007, 129, 5846-5854. [CrossRef] [PubMed]

66. Ruberto, G.; Baratta, M.T. Antioxidant activity of selected essential oil components in two lipid model systems. Food Chem. 2000, 69, 167-174. [CrossRef] 